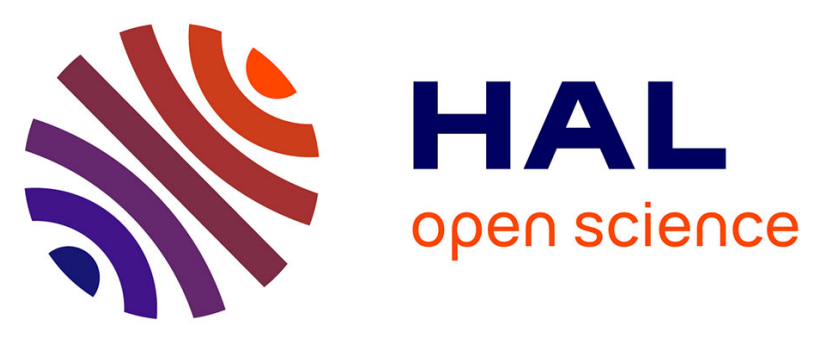

\title{
Study of flame response to transverse acoustic modes from the LES of a 42-injector rocket engine
}

Annafederica Urbano, Quentin Douasbin, Laurent Selle, Gabriel Staffelbach, Bénédicte Cuenot, Thomas Schmitt, Sébastien Ducruix, Sébastien Candel

\section{- To cite this version:}

Annafederica Urbano, Quentin Douasbin, Laurent Selle, Gabriel Staffelbach, Bénédicte Cuenot, et al.. Study of flame response to transverse acoustic modes from the LES of a 42-injector rocket engine. Proceedings of the Combustion Institute, 2017, vol. 36 ( $\mathrm{n}^{\circ} 2$ ), pp. 2633-2639. 10.1016/j.proci.2016.06.042 . hal-01551126

\section{HAL Id: hal-01551126 \\ https://hal.science/hal-01551126}

Submitted on 30 Jun 2017

HAL is a multi-disciplinary open access archive for the deposit and dissemination of scientific research documents, whether they are published or not. The documents may come from teaching and research institutions in France or abroad, or from public or private research centers.
L'archive ouverte pluridisciplinaire HAL, est destinée au dépôt et à la diffusion de documents scientifiques de niveau recherche, publiés ou non, émanant des établissements d'enseignement et de recherche français ou étrangers, des laboratoires publics ou privés. 


\section{OATAO \\ Open Archive Toulouse Archive Ouverte}

\section{Open Archive TOULOUSE Archive Ouverte (OATAO)}

OATAO is an open access repository that collects the work of Toulouse researchers and makes it freely available over the web where possible.

This is an author-deposited version published in : http://oatao.univ-toulouse.fr/ Eprints ID : 17943

To link to this article : DOI:10.1016/j.proci.2016.06.042

URL : http://dx.doi.org/10.1016/j.proci.2016.06.042

To cite this version : Urbano, Annafederica and Douasbin, Quentin and Selle, Laurent and Staffelbach, Gabriel and Cuenot, Bénédicte and Schmitt, Thomas and Ducruix, Sébastien and Candel, Sébastien Study of flame response to transverse acoustic modes from the LES of a 42injector rocket engine. (2017) Proceedings of the Combustion Institute, vol. $36\left(\mathrm{n}^{\circ} 2\right)$. pp. 2633-2639. ISSN 1540-7489

Any correspondence concerning this service should be sent to the repository administrator: staff-oatao@listes-diff.inp-toulouse.fr 


\title{
Study of flame response to transverse acoustic modes from the LES of a 42-injector rocket engine
}

\author{
A. Urbano ${ }^{\text {a }}$, Q. Douasbin ${ }^{\text {b,c }}$, L. Selle ${ }^{\text {b,c,*, G. Staffelbach }}{ }^{\text {d }}$, B. Cuenot ${ }^{\text {d }}$, \\ T. Schmitt ${ }^{\mathrm{e}}, \mathrm{S}$. Ducruix ${ }^{\mathrm{e}}$, S. Candel ${ }^{\mathrm{e}}$ \\ a Safran Tech, E\&P, Rue des Jeunes Bois, Châteaufort, CS 80112, 78772 Magny-Les-Hameaux, France \\ ${ }^{\mathrm{b}}$ Université de Toulouse, INPT, UPS, IMFT (Institut de Mécanique des Fluides de Toulouse), Allée Camille Soula, \\ Toulouse 31400, France \\ ${ }^{\mathrm{c}}$ CNRS, IMFT, Toulouse, 31400, France \\ ${ }^{\mathrm{d}}$ CERFACS, 42 Avenue Gaspard Coriolis, Toulouse Cedex 01 31057, France \\ e Laboratoire EM2C, CNRS, CentraleSupélec, Université Paris-Saclay, Grande Voie des Vignes, Chatenay-Malabry cedex \\ 92295, France
}

\begin{abstract}
The Large-Eddy Simulation of a reduced-scale rocket engine operated by DLR has been conducted. This configuration features 42 coaxial injectors fed with liquid oxygen and gaseous hydrogen. For a given set of injection conditions the combustor exhibits strong transverse thermo-acoustic oscillations that are retrieved by the numerical simulation. The spatial structure of the two main modes observed in the LES is investigated through 3D Fourier analysis during the limit cycle. They are respectively associated with the first transverse and first radial resonant acoustic modes of the combustion chamber. The contributions of each individual flame to the unsteady heat release rate and the Rayleigh index are reconstructed for each mode. These contributions are in both cases low in the vicinity of velocity anti-nodes and high near pressure anti-nodes. Moreover it is noticed that these pressure fluctuations lead to large velocity oscillations in the hydrogen stream. From these observations, a driving mechanism for the flame response is proposed and values for the gain and phase of the associated flame transfer function are evaluated from the LES.
\end{abstract}

Keywords: Large-Eddy Simulation; Rocket propulsion; Transverse combustion instability; Flame transfer function; Rayleigh index

\footnotetext{
* Corresponding author at: Institut de Mécanique des Fluides de Toulouse, Allée Camille Soula, 31400 Toulouse, France. Fax: +33534322994.

E-mail address: laurent.selle@imft.fr (L. Selle).
}

\section{Introduction}

The occurrence of combustion instabilities has plagued many development programs for high-performance propulsion systems [1-4]. In the aerospace industry, one of the most striking examples may be the development of the F1 engine 
for the Apollo mission, which required 1332 fullscale hot-fire tests and 108 injector design changes before meeting both stability and performance requirements [5]. The cost associated with such trial-and-error procedure can be prohibitive justifying the search for methods allowing the prediction of stability characteristics at the design stage.

With growing computational resources available to researchers and engineers, and the development of High Performance Computing, it is timely to address this problem with numerical tools that simultaneously solve for turbulence, acoustics and combustion. Indeed, high fidelity modeling strategies such as Large-Eddy Simulation (LES) have had considerable successes in predicting unstable operating points for gas turbine combustors $[6,7]$ or gaseous coaxial injectors [8-10]. With the recent development of LES for transcritical flows [11-14], high-pressure liquid rocket engine stability can now be numerically studied [15]. Nevertheless, these methods are usually too cumbersome to allow explorations of the whole range of operating conditions. Moreover, it might even be a waste of resources to systematically use LES because it is likely that there are generic features pertaining to the injection units and system or to the combustion chamber, which do not require a high-fidelity simulation to be predicted.

One alternative to this "brute force" approach is the joint use of a flame-response model and an acoustic solver [16]. This has been demonstrated in a generic configuration [17] but also in more complex geometries including turbulent flames [18]. This strategy can help the analysis of unstable modes and deliver good predictions of stability maps [19]. This has also been tried for rocket engine configurations $[9,20]$ with some success. However, two key ingredients are required as inputs for this approach:

1. A baseline flow field. When solving the Helmholtz equation, the field of speed of sound is needed. If linearized Euler equations are chosen, the mean velocity field is also required.

2. A model for the response of the flame to acoustic perturbations. The driving mechanism for the amplification of acoustic perturbations involves the coupling with unsteady heat release rate fluctuations. This often arises through a complex mechanism combining nonlinear fluid mechanics and the flame response to incident acoustic perturbation. A global model for this complex interaction is then required to feed the acoustic solver.

The baseline flow can usually be obtained from lightweight computations or theory, but in some cases high-fidelity simulations are required because it directly influences the eigenfrequency values. However, the flame response is virtually impossible to derive from theoretical considerations, except in some simple cases, and its accurate determination is central to the prediction of stability maps. Experimental determinations are easily obtained for atmospheric pressure systems but there are technical difficulties when operating at high-pressure. This is where the high-fidelity numerical simulations of the "brute force" approach can be of help. In what follows, calculations will not be used to derive stability maps but for more modest goals: (1) Understanding physical mechanisms that drive the flame responses and (2) Obtain a quantitative evaluation of this flame response.

The objective of the present work is to use a time-resolved dataset of $3 \mathrm{D}$ solutions obtained by LES for the study of injector response during the limit cycle of a combustion instability. High-order numerics and state of the art subgrid-scale models ensure the high fidelity character of the database. Also, with the intent to model the unsteady flame response to be fed into an acoustic solver, the question of which flow variables are most relevant is addressed. It is indicated by Yang and Anderson [5, chap. 1, p. 9] that the physical and chemical processes in the immediate vicinity of the chamber backplane are generally quite sensitive to the transverse velocity perturbations parallel to that plane and less susceptible to the unsteady motions acting in the main flow direction at right angles to that plane. On the other hand, much of the work in this domain (e.g. Crocco et al., [21]) emphasizes effects of unsteady pressure as the input for the flame response and this has led to some meaningful results. It is thus interesting to identify the processes that feed energy into the coupling modes and drive the unstable oscillations and more specifically compare effects of transverse velocities with those of pressure perturbations in the near vicinity of the injector backplane. This will be done here by making use of the high-fidelity simulation dataset.

The configuration is briefly presented in Section 2, together with the description of the LES dataset. The limit cycle predicted in the LES is analyzed in Section 3. Section 4 is devoted to the description of the global structure of the flame response and the relative contributions of the two dominant modes are discussed. Finally in Section 5 the physical mechanisms that drive the unsteady flame response are identified, with a focus on the specific injectors that play the most important role in the destabilization of the transverse mode.

\section{Configuration and LES dataset}

The configuration is a reduced-scale rocket engine called BKD operated at DLR Lampoldshausen consisting of a cylindrical combustion chamber, $8 \mathrm{~cm}$ in diameter, fed by 42 coaxial injectors and closed by a choked nozzle. The injection plate pattern comprises three concentric rings of respectively 6,12 and 24 injectors. The 
propellants are oxygen and hydrogen and the BKD is typically operated in the transcritical regime where liquid oxygen at subcritical temperature enters the chamber that is at supercritical pressure. A description of the apparatus can be found in the work of Gröning et al. [22-24]. The operating conditions correspond to an unstable load point referred to as LP4 for which the pressure chamber is $p_{c}=80$ bar and the thermal power assuming complete combustion is around $86 \mathrm{MW}$. The adiabatic burnt-gas temperature assuming complete combustion is $T_{c}=3627 \mathrm{~K}$.

The LES has been carried out with the realgas flow solver AVBP-RG [25] jointly developed by CERFACS, IFPEN and EM2C. A two-step Taylor-Galerkin scheme called TTG4A, is used, which is third order in space and fourth order in time $[26,27]$. The solver accounts for multicomponent real-gas thermodynamics and transport $[28,29]$. The Wall Adapting Linear Eddy (WALE) model is used to close the subgrid stress tensor [30] and an eddy-diffusivity approach is adopted for thermal and species subgrid contributions (constant turbulent Prandtl and Schmidt number: $\left.\mathrm{Pr}_{t}=0.6, \mathrm{Sc}_{t}=0.6\right)$. A infinitely-fast chemistry model [13], relying on the assumption of local chemical equilibrium and a $\beta$-pdf description of the filtered mixture fraction $\widetilde{Z}$, is adopted. Four species are considered $\left(\mathrm{H}_{2}, \mathrm{O}_{2}, \mathrm{OH}\right.$ and $\left.\mathrm{H}_{2} \mathrm{O}\right)$ and source terms are computed following the method described in [13]. This model implies that the anchoring point of the flame is at the location where $\mathrm{O}_{2}$ and $\mathrm{H}_{2}$ streams meet and can therefore not oscillate. Consequently, the influence of flame-root motion on the flame response is not taken into account in this simulation. Specific mass flow rates and temperature of $\mathrm{O}_{2}$ and $\mathrm{H}_{2}\left(\dot{m}_{\mathrm{O}_{2}}=5.75 \mathrm{~kg} . \mathrm{s}^{-1}, \dot{m}_{\mathrm{H}_{2}}=\right.$ $0.96 \mathrm{~kg} . \mathrm{s}^{-1}, T_{\mathrm{O}_{2}}^{i n j}=111 \mathrm{~K}$ and $T_{\mathrm{H}_{2}}^{i n j}=96 \mathrm{~K}$ ) are imposed at the domes manifolds inlets using characteristic treatment of the boundary conditions [31], adapted to real-gas thermodynamics. The outlet nozzle is choked, requiring no boundary treatment. The walls are assumed to be adiabatic and are treated as no-slip boundaries in the injectors and as slip-boundaries in the chamber and in the domes.

The computational domain shown in Fig. 1 is discretized with a $70 \mathrm{M}$ element mesh. The typical mesh resolution in the zone where the flames are established is $\Delta=50 \mu \mathrm{m}$. The resulting CPU requirements are $100,000 \mathrm{~h}$ on a BlueGene $\mathrm{Q}$ for the simulation of $1 \mathrm{~ms}$ (which corresponds to about ten times the period of the typical oscillation at the first transverse mode). A typical run is performed in parallel on 16,384 cores so that the restitution time is reasonable despite the significant computational burden. ${ }^{1}$

\footnotetext{
${ }^{1}$ Because the AVBP solver can make use of hyperthreading on BlueGene Q architectures, there are 4 MPI
}

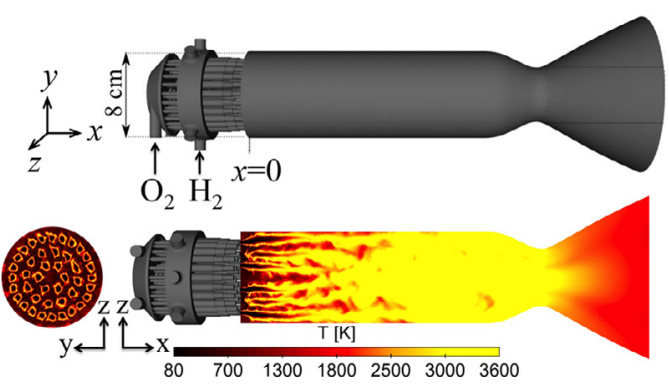

Fig. 1. Overview of the computational domain for the BKD (top). Transverse (bottom left) and longitudinal (bottom right) cuts of instantaneous temperature field.

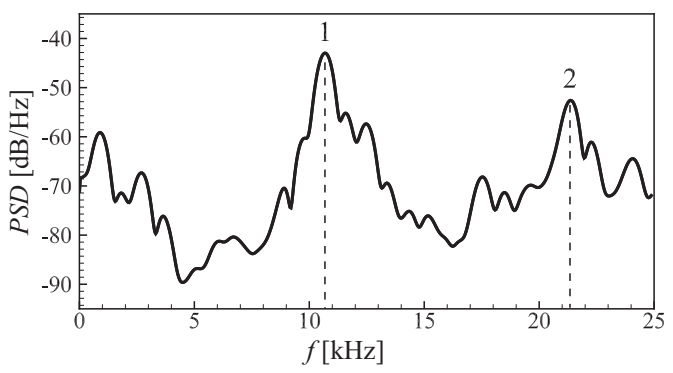

Fig. 2. Power spectral density of pressure fluctuations at the chamber wall $5.5 \mathrm{~mm}$ downstream the injection plate.

A limit cycle is reached in the LES and the dynamics of the system is computed over a period of $7.5 \mathrm{~ms}$. A detailed presentation of this simulation is given in [15] and the aim of the present work is to perform an in-depth analysis of the limit cycle and analyze the flame response. For this purpose, 200 snapshots of the full 3D solution were saved over $2 \mathrm{~ms}$ of the limit cycle (between 5 and $7 \mathrm{~ms}$ ), which corresponds to $330 \mathrm{~Gb}$ of data. Acoustic and combustion fluctuations are analyzed, making use of Fourier transform of the 3D fields (3D-FT) at the frequencies of interest.

\section{Description of the limit cycle}

During the limit-cycle predicted by the LES, pressure fluctuations of very large magnitude are recorded. The rms value reaches $p_{r m s}^{\prime}=0.15 p_{c}$ which corresponds to 10.7 bar. Pressure spikes reaching +44 bar are sometimes observed.

The power spectral density (PSD) of pressure fluctuations at a sensor placed on the chamber wall $5.5 \mathrm{~mm}$ downstream the injector plate is displayed in Fig. 2. There are two dominant frequencies at $f_{1}=10,700 \mathrm{~Hz}$ and $f_{2}=21,400 \mathrm{~Hz}$, which are

processes per core resulting in a total of $65,536 \mathrm{MPI}$ processes for this computation. 


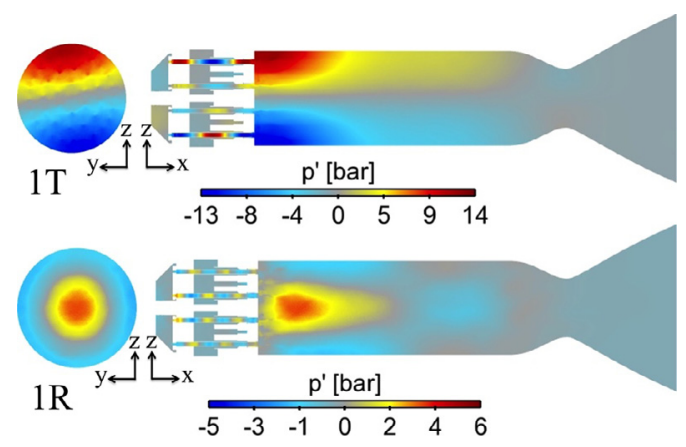

Fig. 3. Spatial structure of the pressure fluctuations for the two dominant frequencies of Fig. 2 from the 3D-FT of 200 instantaneous LES fields.

close and within $5 \%$ of experimentally observed frequencies [22].

It is possible to extract the pressure distributions corresponding to these two frequencies by taking the Fourier transform of the 200 pressure fields accumulated in the dataset. While $f_{1}$ corresponds to the first transverse mode (labeled 1T) of the chamber (Fig. 3), the mode shape at $f_{2}$ resembles the first radial mode (labelled 1R). In both cases these chamber modes are strongly coupled with the oxygen injectors where longitudinal fluctuations are observed. The hydrogen injectors do not seem to be affected by the pressure fluctuations in the chamber, which is consistent with their small radii (of the order of $0.25 \mathrm{~mm}$ ). Nevertheless, an examination of the velocity fields from the PSD (not shown) indicates that the hydrogen stream, at the injector exhaust and further downstream, experiences strong velocity fluctuations because of the eigenmodes in the chamber. This mechanism is discussed in Section 5.

Finally, the mode structures of Fig. 3 suggest that injectors located on the nodal line of the 1T mode will mostly experience transverse velocity fluctuations. Similarly, the $1 \mathrm{R}$ mode will produce a transverse acoustic velocity on the second injector ring.

\section{Maps of flame response}

The objective of this section is to quantify the unsteady response of the flames and deduce maps of the contribution of the two eigenmodes identified in Section 3. To this purpose, it is convenient to define boxes that isolate individual flames. First the three rings are separated by cylindrical boundaries, then neighboring flames by radial planes. All these boundaries are chosen to be at equal distances from neighboring injectors. Various quantities can then be integrated in these boxes over the whole length of the combustion chamber.
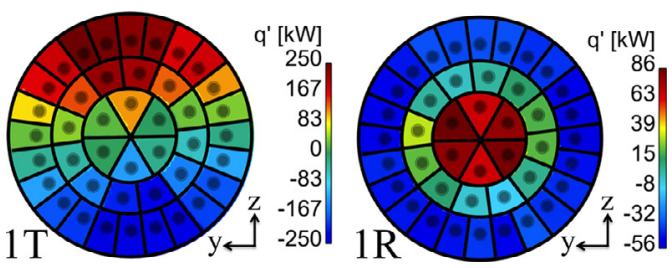

Fig. 4. Maps of unsteady heat release rate integrated around each flame.

This processing method is applied to the unsteady heat release rate, $q^{\prime}$, extracted from the 3D-FT of both modes. The resulting maps of $q^{\prime}$ for each injector and both modes are displayed in Fig. 4. Regarding the 1T mode, the flames that exhibit the greatest response are those located in the region where the pressure fluctuations reach their maximum ( $c f$. Fig. 3). On the nodal line of the pressure field, the flame response is found to nearly vanish. This indicates that the flames respond weakly to the transverse velocity fluctuations of the 1T mode. Similar conclusions are drawn from the map of $q^{\prime}$ in the 1R mode: the inner and outer ring, corresponding to pressure antinodes, respond strongly and out of phase, while the middle injector ring is virtually inactive.

In order to quantify the impact of these fluctuations on the growth of the instability, it is useful to consider the Rayleigh index, defined as: ${ }^{2}$

$R=\frac{1}{T} \frac{\gamma-1}{\gamma p_{0}} \int_{T} \int_{V} p^{\prime}(t) q^{\prime}(t) d V d t$

where $T$ is a time span that covers at least one period of the oscillations and $V$ a volume that contains all the flames. This total Rayleigh index accounting for all pressure and heat release rate perturbation is $R=125 \mathrm{~kW}$ in the LES. This positive value is consistent with the fact that combustion is driving the instability and a limit cycle is reached in the LES. With the intent to separate the impact of the two dominant eigenmodes, the Rayleigh index, $R_{i}$, of each individual mode can be evaluated as:

$R_{i}=\frac{\gamma-1}{2 \gamma p_{0}} \int_{V}\left|\tilde{q}_{i}\right|\left|\tilde{p}_{i}\right| \cos \left(\phi_{\tilde{q}_{i}}-\phi_{\tilde{p}_{i}}\right) d V$

where $\tilde{p}_{i}$ (respectively $\tilde{q}_{i}$ ) is the $3 \mathrm{D}-\mathrm{FT}$ of pressure (respectively heat release rate) fluctuations. The phases $\phi$ correspond to the definition where $\tilde{p}=|\tilde{p}| e^{i \phi}$. Using Eq. (2), the respective contributions of the $1 \mathrm{~T}$ and $1 \mathrm{R}$ modes are $R_{1}=42.2 \mathrm{~kW}$ and $R_{2}=8.8 \mathrm{~kW}$. It follows that both modes are

\footnotetext{
2 This definition would not be consistent with the acoustic energy conservation in a real gas because the normalization $(\gamma-1) /\left(\gamma p_{0}\right)$ corresponds to a perfect gas. Here, we used constant values corresponding to the burnt gases in the chamber. The evaluation of the resulting discrepancies is left to further studies.
} 

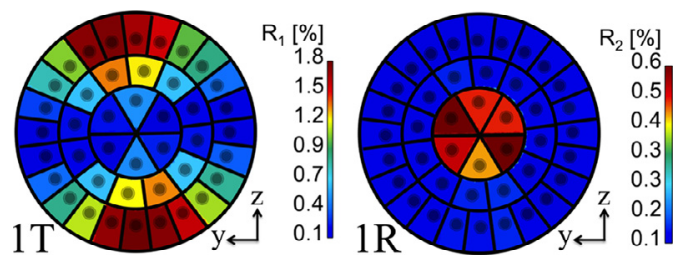

Fig. 5. Maps of individual flames Rayleigh index for both $1 \mathrm{~T}$ and $1 \mathrm{R}$ modes, normalized by the total Rayleigh index of the chamber.

driving the instability and that the $1 \mathrm{~T}$ mode accounts for $33.8 \%$ of the destabilization while the $1 \mathrm{R}$ mode contribution amounts to $7.0 \%$ of the total.

One may now focus on the contribution of individual injectors by examining maps of Rayleigh index integrated around each injector. Figure 5 presents the contributions of the $1 \mathrm{~T}$ and $1 \mathrm{R}$ modes, normalized by the total Rayleigh index.

First, regarding the 1T mode, the shape of $q^{\prime}$ maps is recovered (cf. Fig. 4) with injectors at a pressure antinode contributing the most and those on the nodal line being virtually inactive. The maximum contribution of an individual injector is $1.8 \%$. For the $1 \mathrm{R}$ mode, only the six injectors of the inner ring have a significant contribution, with a maximum of $0.6 \%$. It is interesting to note that despite the high levels of $q^{\prime}$ on the outer ring (cf. Fig. 4), their phase does not seem to allow a significant contribution to the instability.

\section{Individual injector dynamics}

The question that one may now address is that of the physical mechanisms driving the unsteady response of these coaxial flames. The focus is set on the 1T mode, which contributes the most to the driving process, and two typical flames are singled out:

- An A-flame located at a pressure antinode. It was shown in Figs. 4 and 5 that these flames respond strongly to the bulk pressure fluctuation in the chamber.

- An N-flame located at a pressure node. These flames experience little pressure variations but a strong transverse velocity fluctuation. It was shown in Figs. 4 and 5 that they respond weakly in terms of heat release rate fluctuation.

The heat release rate fluctuations $q^{\prime}$, averaged over a volume comprising each flame are compared in Fig. 6, where $q_{0}$ is the time averaged heat release of the flame. As expected, the response of the A-flame is larger, consistently with Fig. 4. This confirms that these coaxial diffusion flames are more sensitive to pressure fluctuations than to the transverse velocity induced by the eigenmode.

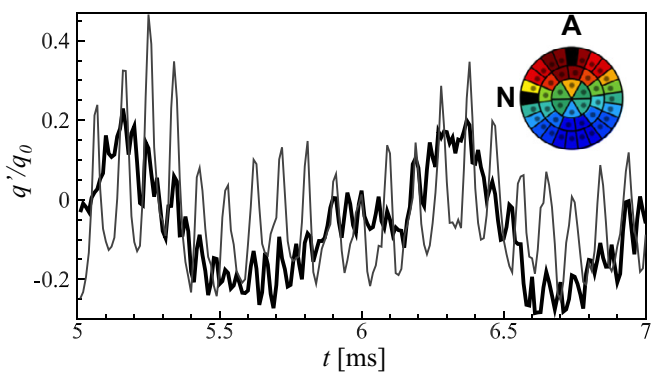

Fig. 6. Comparison of heat release rate fluctuations for a: A-flame; _ N-flame.
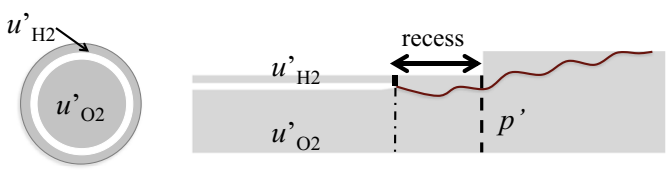

Fig. 7. Schematic of the coaxial injector and reference surfaces for the extraction of velocities and pressure fluctuations used to evaluate the flame responses.

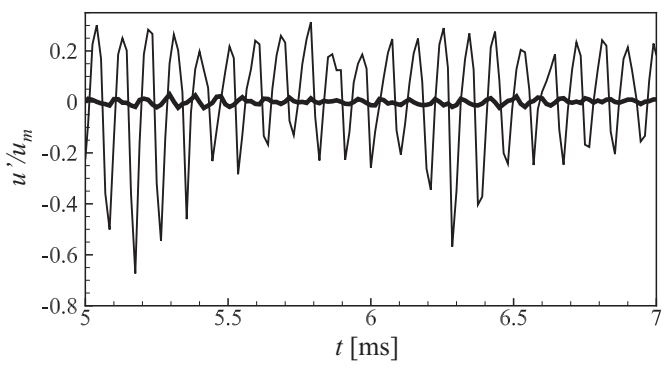

Fig. 8. Velocity fluctuation at the location of the recess: $\longrightarrow u_{\mathrm{H}_{2}}^{\prime} ;-u_{\mathrm{O}_{2}}^{\prime}$.

One may now proceed with a detailed analysis of the A-flame. A schematic representation of the recessed coaxial injector of the BKD is shown in Fig. 7. When an acoustic mode is excited in the combustion chamber, the injector of an A-flame experiences a back-pressure fluctuation, $p^{\prime}$, at its exit plane, which in turn generates velocity fluctuations in both propellant streams. The velocity fluctuations, $u_{\mathrm{H}_{2}}^{\prime}$ and $u_{\mathrm{O}_{2}}^{\prime}$, averaged over their respective cross section (an annulus for $\mathrm{H}_{2}$ and a disk for $\mathrm{O}_{2}$ ), at the location of the recess are compared in Fig. 8. They are normalized by the mean velocity $u_{m}=\left(u_{0, \mathrm{H}_{2}}+u_{0, \mathrm{O}_{2}}\right) / 2$ where subscript 0 indicates a time averaging. This choice for the normalization is supported by the fact that the flow downstream the coaxial injector resembles a pulsated mixing layer. It shows which stream oscillates the most with respect to the mean velocity. When each stream is normalized by its own mean velocity, which is much lower for the dense oxygen, the relative 
fluctuation levels are comparable and around 10\%. It appears that the $\mathrm{O}_{2}$ velocity fluctuations are negligible compared to those of $\mathrm{H}_{2}$. Both streams experience the same pressure perturbation but the corresponding $u^{\prime}$ depends on the impedance which is related both to geometric (area ratios) and thermodynamic (compressibility) effects. Specifically, the $u^{\prime}$ amplitude is inversely proportional to the characteristic impedance of the gas, which is the product of the density and speed of sound: $\rho c$. The thermodynamic conditions at the location of the recess are: $(\rho c)_{\mathrm{O}_{2}}=710^{5} \mathrm{~kg} \cdot \mathrm{m}^{-2} \cdot \mathrm{s}^{-1}$ and $(\rho c)_{\mathrm{H}_{2}}=1.810^{4} \mathrm{~kg} \cdot \mathrm{m}^{-2} \cdot \mathrm{s}^{-1}$, which is 40 times higher for $\mathrm{O}_{2}$ than for $\mathrm{H}_{2}$. This possibly explains why the velocity fluctuations in the $\mathrm{H}_{2}$ stream dominate in the present conditions.

To quantify the correlation between velocities or pressure and heat release perturbations one may calculate the normalized cross correlation defined by:

$r_{f g}=\frac{(f \star g)(\tau)}{\sigma_{f} \sigma_{g}}$

where $\sigma$ is the standard deviation. The maximum correlation between $p^{\prime}$ and $q^{\prime}$ is $r_{p q}=80 \%$ while it is $67 \%$ between $u_{\mathrm{H}_{2}}^{\prime}$ and $q^{\prime}$ and falls down to $47 \%$ between $u_{\mathrm{O}_{2}}^{\prime}$ and $q^{\prime}$. These observations are confirmed by single injector simulations (not shown here), where the flame responses induced by $\mathrm{H}_{2}$ or $\mathrm{O}_{2}$ streams fluctuations are compared. Forcing the individual propellants velocities at the level measured in the full engine, i.e. around $10 \%$ of their mean, yields a much weaker flame response for $\mathrm{O}_{2}$ than for $\mathrm{H}_{2}$. Nevertheless bulk pressure fluctuations at the outlet of the injector also triggered significant levels of $q^{\prime}$.

From these observations we can assume that $u_{\mathrm{O}_{2}}^{\prime}$ is not the most relevant input variable for the flame response. One may then speculate that $q^{\prime}$ is driven by $u_{\mathrm{H}_{2}}^{\prime}$ through the forcing of the shear layer, generating unsteady coherent structures affecting both wrinkling and local stretch of the flame eventually leading to heat release rate fluctuations. A mechanism for the flame response is now proposed, based on the above rationale. Hydrogen velocity fluctuations are supposed to be central in this mechanism but the validation of this hypothesis requires additional tests. Mechanisms involving a direct response to pressure fluctuations, for example, should also be considered. The mechanism is summarized in Fig. 9, where the temporal evolution of $p^{\prime}, u_{\mathrm{H}_{2}}^{\prime}$ and $q^{\prime}$, extracted from the FT at the 1T frequency, are shown over two cycles of the instability. Three time delays are identified:

- The delay of $u_{\mathrm{H}_{2}}^{\prime}$ with respect to $p^{\prime}: \tau_{u p}$.

- The delay of $q^{\prime}$ with respect to $u_{\mathrm{H}_{2}}^{\prime}: \tau_{q u}$.

- The delay of $q^{\prime}$ with respect to $p^{\prime}: \tau_{q p}$.

Figure 9 suggests the present scenario for the A-flame response: the pressure fluctuation at the

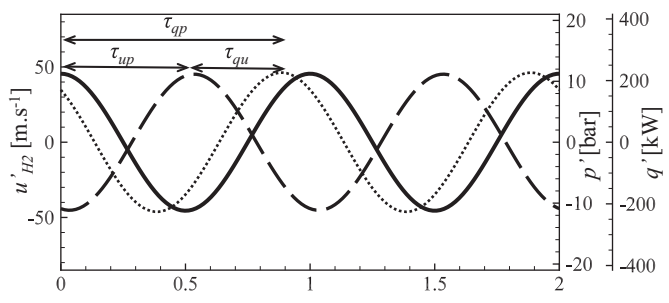

Fig. 9. Fluctuations over two periods of the $1 \mathrm{~T}$ mode $\left(T=1 / f_{1}\right)$ for an A-flame: $p^{\prime} ;-u_{\mathrm{H}_{2}}^{\prime} ; \ldots \ldots q^{\prime}$. Reference surfaces are indicated in Fig. 7.

injector outlet generates a hydrogen velocity fluctuation after a time $\tau_{u p}$, which drives the shear layer and subsequently heat release rate fluctuations with a delay $\tau_{q u}$. The overall delay $\tau_{q p}=\tau_{u p}+\tau_{q u}$ is such that $p^{\prime}$ and $q^{\prime}$ are almost perfectly in phase, resulting in a positive Rayleigh index. While $\tau_{u p}$ is mainly acoustic by nature, $\tau_{q u}$ represents the time for hydrodynamics and combustion to respond to the unsteady shear.

Finally, the overall response of an A-flame can be quantified by the gain, $n$ and time delay, $\tau$ of $q^{\prime}$ versus $p^{\prime}$ :

$n=\frac{|\tilde{q}| / q_{0}}{|\tilde{p}| / p_{0}} \quad \tau=\frac{\phi_{\tilde{q}}-\phi_{\tilde{p}}}{2 \pi f}$

The present dataset is used to compute $n$ and $\tau$ for the A-flames of the 1T mode. Here we give averaged values for the 8 outer A-flames that have the highest Rayleigh index (red regions in Fig. 5): $n=1.1$ and $\tau=0.9 T$.

\section{Conclusions}

In this article, the Large-Eddy Simulation of a 42 -injector reduced-scale rocket engine is used to analyze the limit cycle of a combustion instability. The post-processing of a time-resolved dataset of $3 \mathrm{D}$ solutions allows to isolate individual flame dynamics as well as the influence of different eigenmodes of the chamber. In this configuration two chamber modes dominate, one with a transverse shape and the other with a radial structure. For both modes, the magnitude of the flame response is maximum at pressure antinodes while the flames located at a pressure node respond weakly, suggesting that the lateral motion caused by transverse velocity fluctuations does not effectively feed energy into acoustics for sustaining this instability. A mechanism is proposed in which the bulk pressure variation at the injector outlet generates unsteady shear through the variation of the hydrogen velocity, ultimately resulting in heat release rate fluctuations. For modeling purposes, it is suggested to consider the fluctuating pressure in the injection plane as the relevant input for the flame response. 
This option has been considered since the early studies on transverse combustion instabilities in rocket engines [21] and it receives here additional support from 3D unsteady numerical simulation.

\section{Acknowledgments}

This investigation was carried out in the framework of the French-German REST program initiated by CNES, DLR, Astrium and Snecma. Support provided by Safran (Snecma) the prime contractor of the Ariane rocket propulsion system is gratefully acknowledged.

All geometrical, operational, and measurement data related to the BKD was kindly provided by DLR Lampoldshausen. The authors are particularly grateful to Stefan Gröning and colleagues who performed the experiments and formulated the test case.

The authors acknowledge PRACE for awarding us access to resource FERMI based in Italy at Cineca. This work was granted access to the high-performance computing resources of IDRIS under the allocation x20152b7036 made by Grand Equipement National de Calcul Intensif.

The research leading to these results has received funding from the European Research Council under the European Union's Seventh Framework Programme (FP/2007-2013) / ERC Grant Agreement ERC-AdG 319067-INTECOCIS.

\section{References}

[1] F. Culick, Unsteady Motions in Combustion Chambers for Propulsion Systems, agardograp edition, NATO/RTO-AG-AVT-039, 2006.

[2] T. Poinsot, D. Veynante, Theoretical and Numerical Combustion, third edition, Thierry Poinsot, 2011. www.cerfacs.fr/elearning.

[3] T.C. Lieuwen, Unsteady Combustor Physics, Cambridge University Press, 2012.

[4] S. Candel, D. Durox, T. Schuller, N. Darabiha, L. Hakim, T. Schmitt, Eur. J. Mech. - B/Fluids 40 (2013) 87-106, doi:10.1016/j.euromechflu.2013. 01.002 .

[5] W.E. Anderson, V. Yang, Liquid Rocket Engine Combustion Instability, 169, progress i edition, American Institute of Aeronautics and Astronautics, Washington DC, 1995, doi:10.2514/4.866371.

[6] P. Wolf, G. Staffelbach, L.Y. Gicquel, J.-D. Müller, T. Poinsot, Combust. Flame 159 (11) (2012) 33983413, doi:10.1016/j.combustflame.2012.06.016.

[7] B. Franzelli, E. Riber, L.Y.M. Gicquel, T. Poinsot, Combust. Flame 159 (2) (2012) 621-637, doi:10.1016/ j.combustflame.2011.08.004.
[8] M.E. Harvazinski, W.E. Anderson, C.L. Merkle, J. Propuls. Power 29 (2) (2013) 396-409, doi:10.2514/1. B34732.

[9] L. Selle, R. Blouquin, M. Théron, L.-H. Dorey, M. Schmid, W. Anderson, J. Propuls. Power 30 (4) (2014) 978-990, doi:10.2514/1.B35146.

[10] S. Srinivasan, R. Ranjan, S. Menon, Flow Turbul. Combust. 94 (1) (2015) 237-262, doi:10.1007/ s10494-014-9569-x.

[11] J. Oefelein, Combust. Sci. Technol. 178 (1) (2006) 229-252, doi:10.1080/00102200500325322.

[12] M. Masquelet, S. Menon, Y. Jin, R. Friedrich, Aerosp. Sci. Technol. 13 (8) (2009) 466-474, doi:10. 1016/j.ast.2009.07.005.

[13] T. Schmitt, Y. Méry, M. Boileau, S. Candel, Proc. Combust. Inst. 33 (1) (2011) 1383-1390, doi:10.1016/ j.proci.2010.07.036

[14] L. Hakim, A. Ruiz, T. Schmitt, et al., Proc. Combust. Inst. 35 (2) (2015) 1461-1468, doi:10.1016/j. proci.2014.05.142

[15] A. Urbano, L. Selle, G. Staffelbach, et al., Combust. Flame 169 (2016) 129-140.

[16] J. O'Connor, V. Acharya, T. Lieuwen, Prog. Energy Combust. Sci. 49 (2015) 1-39, doi:10.1016/j. pecs.2015.01.001.

[17] N. Noiray, D. Durox, T. Schuller, S. Candel, J. Fluid Mech. 615 (2008) 139, doi:10.1017/ S0022112008003613.

[18] L. Selle, L. Benoit, T. Poinsot, F. Nicoud, W. Krebs, Combust. Flame 145 (1-2) (2006) 194-205, doi:10. 1016/j.combustflame.2005.10.017.

[19] C.F. Silva, F. Nicoud, T. Schuller, D. Durox, S. Candel, Combust. Flame 160 (9) (2013) 1743-1754, doi:10.1016/j.combustflame.2013.03.020.

[20] J. Pieringer, T. Sattelmayer, F. Fassl, J. Propuls. Power 25 (5) (2009) 1020-1031, doi:10.2514/1.38782.

[21] L. Crocco, D.T. Harrje, F.H. Reardon, ARS J. 32 (3) (1962) 366-373, doi:10.2514/8.6022.

[22] S. Gröning, D. Suslov, M. Oschwald, T. Sattelmayer, in: 5th European Conference for Aeronautics and Space Sciences, Munich, 2013.

[23] S. Gröning, D. Suslov, J. Hardi, M. Oschwald, in: Proceedings Space Propulsion, Association aéronautique et astronautique de France (3AF), Cologne, 2014.

[24] S. Gröning, J.S. Hardi, D. Suslov, M. Oschwald, J. Propuls. Power 32 (3) (2016) 560-573.

[25] T. Schmitt, L. Selle, A. Ruiz, B. Cuenot, AIAA J. 48 (9) (2010) 2133-2144, doi:10.2514/1.J050288.

[26] L. Quartapelle, V. Selmin, Finite Elements in Fluids 76 (90) (1993) 46.

[27] O. Colin, M. Rudgyard, J. Comput. Phys. 162 (2) (2000) 338-371, doi:10.1006/jcph.2000.6538.

[28] G. Soave, Chem. Eng. Sci. 27 (6) (1972) 1197-1203.

[29] T.H. Chung, M. Ajlan, L.L. Lee, K.E. Starling, Ind. Eng. Chem. Res. 27 (4) (1988) 671-679, doi:10.1021/ ie $00076 \mathrm{a} 024$

[30] F. Nicoud, F. Ducros, Flow Turbul. Combust. 62 (3) (1999) 183-200, doi:10.1023/A:1009995426001.

[31] T. Poinsot, S. Lele, J. Comput. Phys. 101 (1) (1992) 104-129, doi:10.1016/0021-9991(92)90046-2. 